\title{
Efeitos das Condições de Preparação e de Modificação de Superfície de Membranas de PEUAPM na Separação Água/Óleo
}

\author{
Laura H. de Carvalho, Tatianny S. Alves, Tânia L. Leal, Hélio de L. Lira \\ Unidade Acadêmica de Engenharia de Materiais, UFCG
}

\begin{abstract}
Resumo: Baixos custos operacionais, operação relativamente simples, scale-up e manutenção são as principais razões para uso de membrana no processo de separação numa variedade ampla de aplicações, incluindo purificação de efluentes aquosos. Neste trabalho, a influência dos parâmetros de processo na preparação de membranas de PEUAPM simétricas e assimétricas foi investigada. Membranas de PEUAPM tubulares simétricas foram preparadas com pó passante em peneiras de malha \# 80 e \# 100. As condições de processamento foram: a) temperatura $\left(200\right.$ e $\left.220{ }^{\circ} \mathrm{C}\right)$; b) pressões de compactação $\left(0,4\right.$ e $\left.6 \mathrm{kgf} / \mathrm{cm}^{2}\right)$; e c) tempo de sinterização (90 minutos). Membranas assimétricas foram obtidas por deposição de um filme de PEAD sobre a superfície interna das membranas simétricas selecionadas. As Membranas foram caracterizadas por MEV, porosimetria de mercúrio e medidas de fluxo. Nossos dados indicam que, para membranas simétricas, a porosidade e fluxo permeado diminuíram com o aumento da temperatura e pressões de compactação. Redução mais acentuada nestas variáveis foi observada com membranas assimétricas.
\end{abstract}

Palavras-chave: Compactação, deposição, membranas, PEUAPM, sinterização.

\section{Preparation and Surface Modification Effects of UHMWPE Membranes for Oil/Water Separation}

\begin{abstract}
Low operational costs, relatively simple operation, scale-up and maintenance are the main reason for using membrane separation processes in a wide range of applications. The purpose of this work was to prepare, characterize and investigate the influence of processing parameters $(T, P)$ and of an internal surface modification on the performance of UHMWPE membranes. Sinterization was the technique used for membrane preparation. Tubular sintered UHMWPE membranes were prepared with powders sieved through \#80 and \#100 mesh. Processing conditions were: a) temperature (200 and $\left.220{ }^{\circ} \mathrm{C}\right)$; b) compacting pressures $\left(0,4\right.$ and $\left.6 \mathrm{kgf} / \mathrm{cm}^{2}\right)$; and c) sintering time (90 minutes). Surface modified membranes were obtained by internally impregnating selected UHMWPE membranes with a HDPE dilute solution. Membranes were characterized by SEM, mercury porosimetry water flux. Our data indicate that, porosity and permeate flux decreased with increasing temperature and compacting pressures as well as with membrane internal surface impregnation.
\end{abstract}

Keywords: Compacting, water flux, membranes, UHMWPE, sintering.

\section{Introdução}

Os processos de separação com membranas (PSM) podem ser empregados em um vasto número de aplicações em diferentes áreas, tais como: médica, biológica e farmacêutica, e em indústrias químicas e de alimentos ${ }^{[1,2]}$. Os PSM apresentam uma série de vantagens em relação aos processos de separação tradicionais. São processos onde a separação ocorre, normalmente, sem que haja mudança de fase, economizando energia, e as propriedades das membranas podem ser ajustadas de acordo com a aplicação em questão ${ }^{[3,4]}$.

Dentre as técnicas mais utilizadas para preparar membranas a partir de poliolefinas encontram-se as de irradiação, extrusão e, eventualmente, de sinterização ${ }^{[5]}$. A sinterização consiste na fusão incipiente de materiais pulverulentos de granulometria controlada. A porosidade final da membrana e o tamanho médio dos poros dependem, entre outros fatores, do material, da granulometria do pó, da temperatura, e do tempo de residência nesta temperatura ${ }^{[6,7-12]}$.

As membranas preparadas pela técnica de sinterização são as de preparo mais simples, já que o processo não envolve outras etapas, tais como: precipitação, gelificação, etc. Esta técnica gera uma estrutura microporosa, de porosidade relativamente baixa, na escala de 10 a 40\%, e uma estrutura irregular de poros com distribuição de tamanho muito largo ${ }^{[7]}$.

O tamanho das partículas do pó é o principal parâmetro que determina os tamanhos dos poros da membrana final, obtida com esta técnica, que pode ser aplicada a materiais metálicos, cerâmicos ou poliméricos.

Autor para correspondência: Laura H. de Carvalho, Unidade Acadêmica de Engenharia de Materiais, UFCG, Caixa Postal 10034, CEP: 58109-970, 
A sinterização é um dos únicos processos em que se podem utilizar polímeros com altíssima massa molar, e cujo processamento não é viável por métodos de processamento comuns $^{[8]}$.

A busca de novos materiais e novas técnicas para produção de membranas é fonte de interesse de vários grupos de pesquisas acadêmicas e industriais, e são crescentes os estudos que têm sido realizados sobre o uso de membranas de natureza diversa para as mais variadas aplicações.

O polietileno de ultra-alta massa molar (PEUAPM) é um polímero da classe das poliolefinas e tem sido utilizado com sucesso em vários tipos de aplicações devido à sua combinação única de propriedades físicas e mecânicas, atribuídas principalmente à sua alta massa molar. Este é considerado um material inovador e bastante promissor, pelas seguintes características: resistente à compressão, abrasão, extremamente resistente a uma ampla gama de produtos químicos, e se destaca por uma ótima relação custo/benefício ${ }^{[10]}$.

Trabalhos sobre a preparação de membranas poliméricas por sinterização, de forma geral, são escassos já que a técnica é pouco empregada com materiais poliméricos, devido a dificuldades associadas ao controle e homogeneidade do tamanho dos poros durante a sinterização destes materiais. As características do PEUAPM, contudo, tornam o uso desta técnica viável para processamento deste material.

Estudos anteriores, realizados em nosso grupo, por Souto et al. (2002), revelaram que o desempenho das membranas confeccionadas não era satisfatório, o que foi atribuído aos tamanhos de grãos e de poros inadequados ${ }^{[11]}$. Naquele estudo, foram utilizadas membranas sinterizadas tubulares a base de PEUAPM, obtidas a partir de amostras fornecidas pela Braskem e codificadas de 3040 e 6540, tal como recebidas (sem peneiramento), e com amostras passantes em peneiras de malha \#80 e \#100. Posteriormente, estudos realizados por Leal (2007) sobre os efeitos do tempo e temperatura de sinterização na porosidade deste tipo de membranas indicaram que o aumento do tempo e da temperatura de sinterização, apesar de não reduzirem o diâmetro médio dos poros, afetavam a porosidade das membranas ${ }^{[9]}$ e que a seletividade destas ainda era inadequada, de modo que outras técnicas teriam de ser adotadas para adequá-las aos fins propostos.

O interesse por técnicas de modificação de superfícies é evidenciado pelo grande número de pesquisas realizadas nas últimas décadas. Estas técnicas permitem controlar e/ou modificar características superficiais de materiais, tornando-os mais eficientes e/ou adequados a várias aplicações ${ }^{[13,14]}$.

Neste trabalho, membranas poliméricas de polietileno de ultra-alta massa molar (PEUAPM) foram preparadas sob distintas condições experimentais e suas superfícies internas foram modificadas por impregnação com solução diluída de PEAD em tolueno. O desempenho destas membranas foi avaliado através de medidas de fluxo permeado e de seletividade na separação de uma mistura água/óleo.

\section{Experimental}

\section{Materiais}

O polietileno de ultra-alta massa molar - PEUAPM (código 3041) foi fornecido pela Braskem S. A., em forma de pó, possui massa molar de $3 \times 10^{8} \mathrm{~g} \cdot \mathrm{mol}^{-1}$, tamanho médio de partículas entre 150-100 $\mu \mathrm{m}$, densidade aparente maior do que $0,4 \mathrm{~g} / \mathrm{cm}^{3}$ e viscosidade intrínseca $14,8 \mathrm{dl} / \mathrm{g}$. O pó foi classificado por tamanho através de peneiramento e as frações utilizadas foram: a) passante em peneiras ABNT \#80 e retida em peneira $\mathrm{ABNT} \# 100$, ou seja, com grãos de tamanhos entre 180 e $150 \mu \mathrm{m}(180>\mathrm{x}>150 \mu \mathrm{m})$; e b) passante em peneira ABNT \#100, ou seja, com grãos menores do que $150 \mu \mathrm{m}$. O PEAD, catalogado como JV 060U, utilizado para modificar a superfície interna da membrana também foi fornecido pela Braskem S.A., e apresenta índice de fluidez de 0,06 a $75 \mathrm{~g} / 10 \mathrm{~min}$ (ASTM D-1238) e uma temperatura de fusão de 110 a $127^{\circ} \mathrm{C}$.

\section{Métodos}

\section{Preparação das membranas}

As membranas foram preparadas em um molde metálico como ilustrado na Figura 1. As dimensões finais das membranas foram de: $9,88 \mathrm{~mm}$ de diâmetro externo, 6,70 $\mathrm{mm}$ de diâmetro interno, ou seja, com espessura de parede de $1,59 \mathrm{~mm}$, e altura em torno de $97 \mathrm{~mm}$. As amostras foram sinterizadas nas temperaturas de 200 e $220{ }^{\circ} \mathrm{C}$ por um tempo de 90 minutos. Após a sinterização as membranas foram compactadas num sistema pneumático de pressão, ilustrado na Figura 2, sob pressões de compactações de 4 e $6 \mathrm{Kgf} / \mathrm{cm}^{2}$. Os efeitos da compactação na morfologia e no desempenho das membranas foram observados através de análise por MEV (equipamento Shimadzu Superscan SSX-550), porosimetria de mercúrio (porosímetro Auto Pore 9400 da marca Micromeritics) e medidas de fluxo permeado, sendo utilizado um sistema de caracterização de permeabilidade hidráulica das membranas, como ilustrado na Figura 3. As medidas de fluxo permeado foram determinadas com água destilada, em temperatura ambiente e diferença de pressão através da membrana de 1 bar. $\mathrm{O}$ ensaio de seletividade foi feito com efluente sintético formulado com 1000 ppm de óleo comercial para motores automotivos em água destilada. A concen-

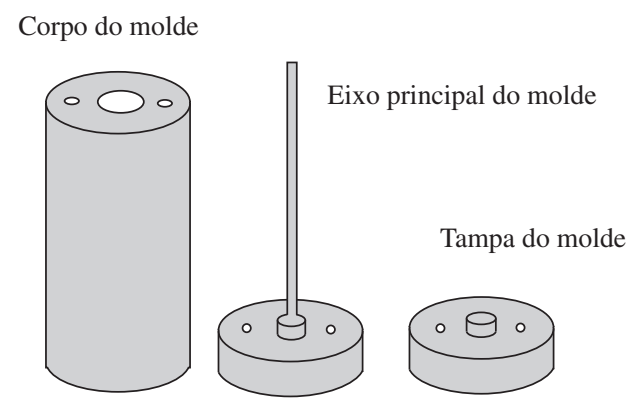

Figura 1. Molde utilizado para a fabricação das membranas de PEUAPM. 


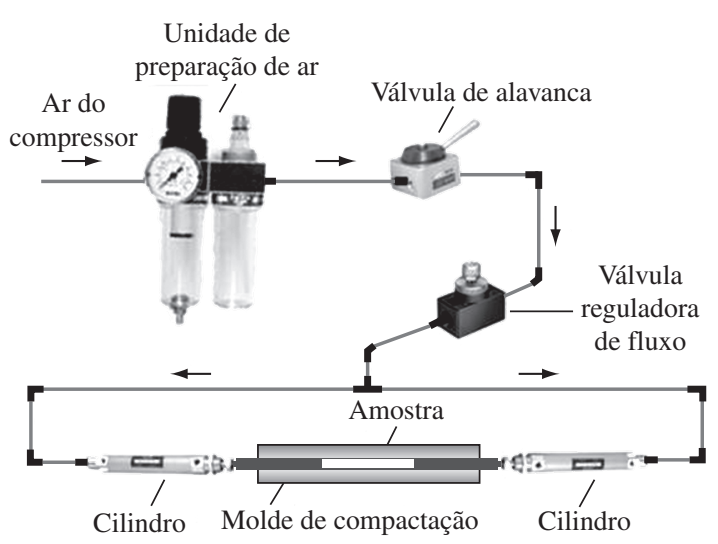

Figura 2. Sistema pneumático de pressão.

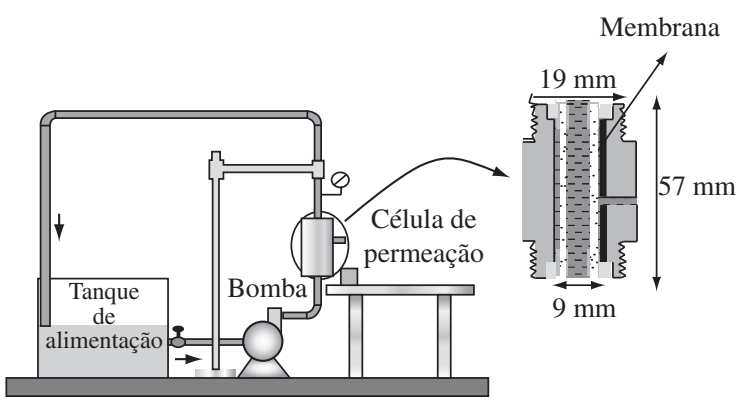

Figura 3. Sistema utilizado nos testes de caracterização da permeabilidade hidráulica das membranas.

tração de óleo remanescente no permeado foi determinada no analisador de óleo Horiba OCMA - 350. Para cada ensaio de medida de fluxo permeado e seletividade foram testadas 6 membranas.

\section{Modificação das membranas}

Visando reduzir o tamanho de poros das membranas de PEUAPM, uma modificação da superfície interna das membranas foi realizada por impregnação com solução diluída de PEAD em tolueno. Para tanto, uma solução de PEAD em tolueno $\left(1,0 \mathrm{~g} . \mathrm{L}^{-1}\right)$ foi preparada a quente $\left(135^{\circ} \mathrm{C}\right)$ e deixada resfriar a temperatura ambiente. Com uma extremidade da membrana fechada, a solução foi vertida no interior da membrana, onde permaneceu por 15 segundos. Decorrido este tempo a solução foi deixada escoar e a membrana deixada secar na temperatura ambiente até a remoção total de tolueno. O efeito da impregnação foi observado através de MEV e de medidas de fluxo permeado (água) e de seletividade (água/óleo).

\section{Resultados e Discussão}

\section{Caracterização das membranas de PEUAPM}

Efeito da aplicação de pressões de compactação na morfologia das membranas

As Figuras 4a, b ilustram os resultados obtidos dessa caracterização para as membranas manufaturadas com pó passante em malha \# 100 a $220{ }^{\circ} \mathrm{C}$ e sinterizadas durante

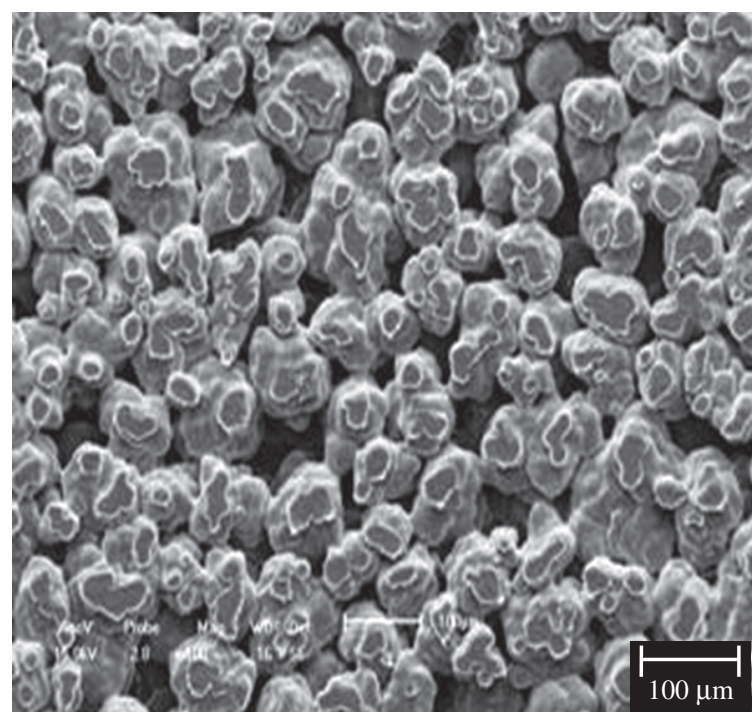

(a)

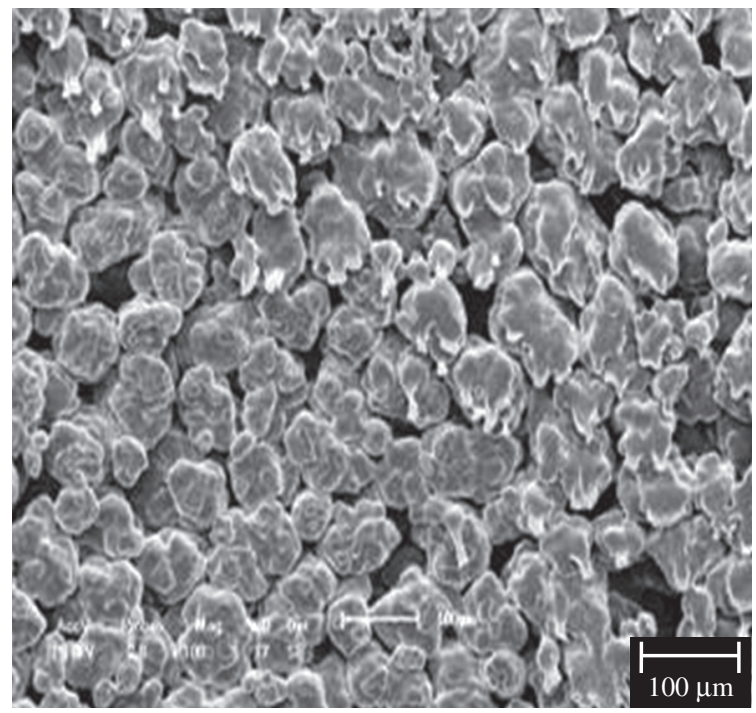

(b)

Figura 4. Microscopia Eletrônica de Varredura das membranas de PEUAPM sinterizadas sob temperatura de $220^{\circ} \mathrm{C}$ durante 90 minutos: a) sem compactação; e b) com compactação de $6 \mathrm{kgf} / \mathrm{cm}^{2}$.

90 minutos, sem e com aplicação de uma pressão de compactação de $6 \mathrm{kgf} / \mathrm{cm}^{2}$, respectivamente. Todas as micrografias apresentadas têm aumento de 100x.

Observa-se, através da Figura 4, que a aplicação de uma pressão de compactação promoveu um maior aumento na área de contato entre os grãos. A Figura $4 \mathrm{~b}$ evidencia que a estrutura da amostra compactada é heterogênea, pois se percebe tanto formação de pescoço (canto esquerdo superior) quanto à presença de zonas de sobreposição de grãos (canto direito inferior), bem como a existência de poros grandes e pequenos. Estes dados indicam que a compressão, tal como aplicada, não levou a uma redução expressiva ou uniforme no tamanho de poros ou na estrutura da membrana, ou seja, não houve influência significativa da pressão de compactação no tamanho médio dos poros das membranas. 
Tabela 1. Diâmetro médio dos poros e porosidade das membranas simétricas de PEUAPM.

\begin{tabular}{ccc}
$\begin{array}{c}\text { Membrana simétrica de } \\
\text { PEUAPM }\end{array}$ & $\begin{array}{c}\text { Diâmetro } \\
\text { médio de } \\
\text { poros }(\mu \mathbf{m})\end{array}$ & Porosidade (\%) \\
\hline Membrana não compactada & 21,10 & 34,46 \\
Membrana compactada & 21,10 & 29,50 \\
\hline
\end{tabular}

Figura 5. Representação esquemática do processo de sinterização, com formação de pescoço entre as partículas e arredondamento dos poros.

A Tabela 1 ilustra o efeito da compactação na porosidade das membranas manufaturadas com pó passante em malha \#100 e sinterizadas nas condições de $220^{\circ} \mathrm{C}$ por 90 minutos. Os dados da análise de porosimetria de mercúrio, expressos na Tabela 1 , indicam que a porosidade média das membranas foi reduzida com aumentos na pressão de compactação.

A porosidade é um indicativo do estado de compactação (empacotamento) das partículas e, em princípio, partículas menores associadas a maiores temperaturas de sinterização levam a uma redução da porosidade, principalmente quando estas são submetidas às pressões de compactação mais elevadas. Nossos dados, portanto, indicam que a aplicação de pressão de compactação imediatamente após a sinterização das membranas levou a um melhor empacotamento das partículas, ao mesmo tempo em que foi incapaz de reduzir, uniforme ou significativamente, o tamanho dos poros.

Estes resultados justificam a redução do fluxo do permeado com a aplicação de pressões de compactação, como mostrado nas Figuras 4 e 5.

Estudos realizados por Islabão $(2005)^{[16]}$ indicaram que as partículas de PEUAPM ao serem aquecidas apresentaram grande dificuldade de escoamento, devido à elevada massa molar e, consequentemente, alta viscosidade do fundido. As observações feitas por Islabão se confirmam neste trabalho, pois se verificou que aumentos na temperatura de sinterização, associada à compactação das membranas promoveu uma redução na porosidade da membrana, sem que ocorresse uma minimização do tamanho de poros. A explicação para estes resultados se deve a forma como o PEUAPM se comporta durante sua fusão incipiente, ou seja, ocorre a formação de pescoço a partir dos pontos de contatos das partículas durante a sinterização de forma que os poros são arredondados, sem que ocorra uma redução no diâmetro hidráulico dos poros da membrana sinterizada como mostra a representação esquemática da Figura 5.

Efeito da impregnação de um filme de PEAD na morfologia das membranas simétricas

As superfícies internas de membranas selecionadas foram modificadas por impregnação com uma solução de PEAD dissolvido em tolueno na concentração de 1,0 g. $\mathrm{L}^{-1}$.

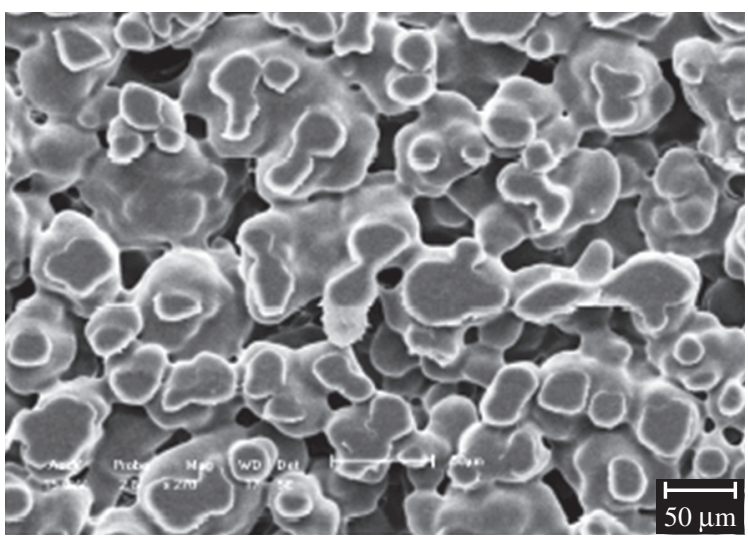

(a)

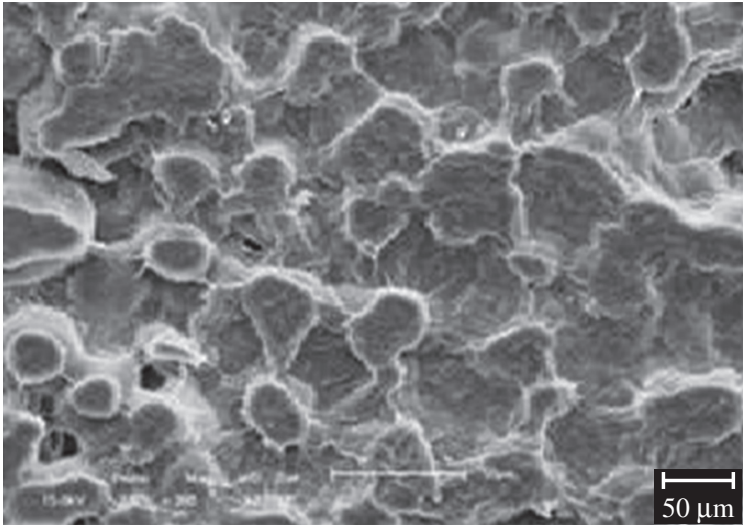

(b)

Figura 6. Microscopia eletrônica de varredura das membranas de PEUAPM sinterizadas sob temperatura de $220{ }^{\circ} \mathrm{C}$ durante 90 minutos: a) sem deposição; e b) com deposição de filme de PEAD na concentração de 1,0 g.L $\mathrm{L}^{-1}$.

O efeito desta modificação na morfologia de membranas de PEUAPM manufaturadas com pó passante em malha \# 100 e sinterizadas a $220{ }^{\circ} \mathrm{C}$ durante 90 minutos foi avaliado e ilustrado através das micrografias apresentadas na Figura 6 e que têm aumento de 270x.

Observa-se que a impregnação do PEAD na superfície interna da membrana, levou a uma redução do tamanho dos poros, o que é coerente com as reduções significativas observadas no fluxo do permeado através das membranas modificadas, como ilustrado nas Figuras 7 e 8.

\section{Avaliação do fluxo do permeado através das membranas}

Os resultados das medidas de fluxos através das membranas modificadas e não modificadas estão ilustrados nas Figuras 7 e 8.

Nos ensaios de medida de fluxo permeado com água destilada, observou-se que a aplicação de uma pressão de compactação após a sinterização levou a uma redução do fluxo através das membranas e que reduções mais acentuadas foram obtidas para membranas compactadas sob pressões mais elevadas $\left(6 \mathrm{Kgf} / \mathrm{cm}^{2}\right)$. Este comportamento era esperado já que, na compactação de um material granular, a diminuição 


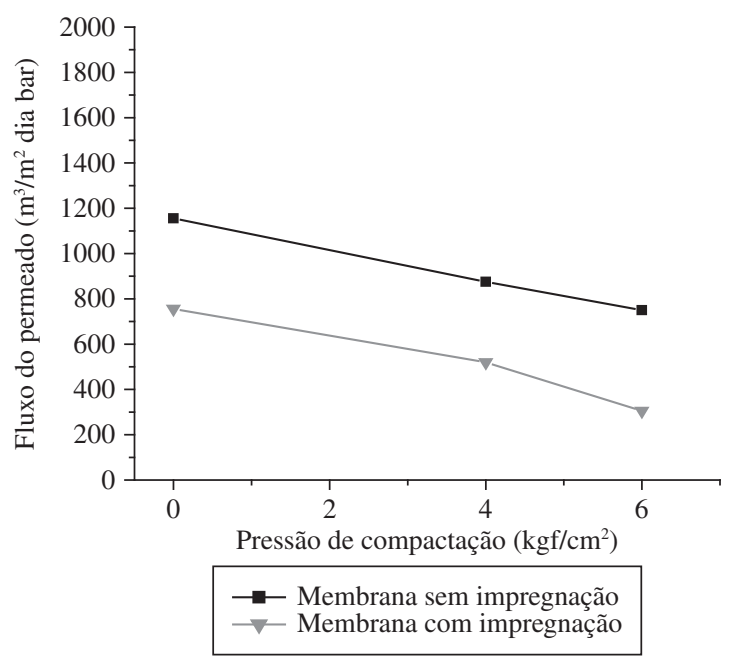

(a)

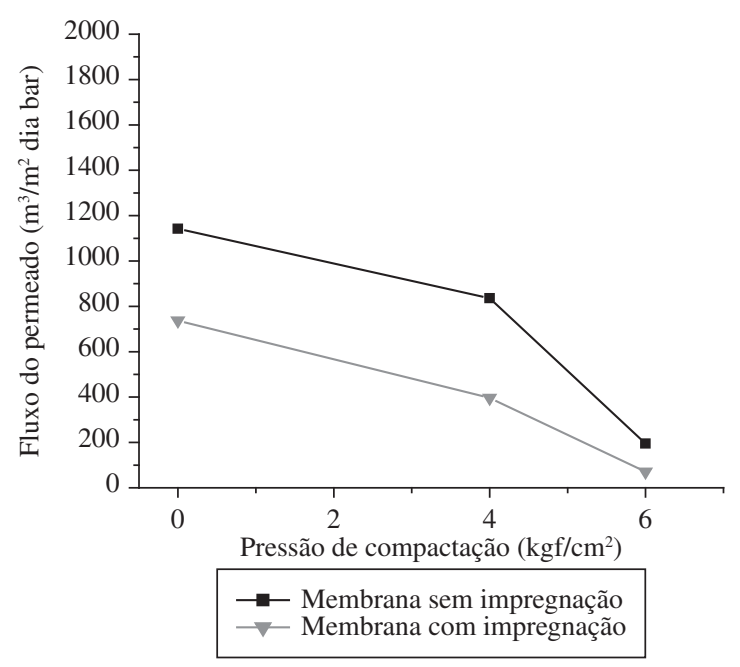

(b)

Figura 7. Efeito da compactação e da aplicação de um filme de PEAD no fluxo permeado com água destilada das membranas de PEUAPM 3041 sinterizadas a $200{ }^{\circ} \mathrm{C}$ durante 90 minutos: a) \# 80; e b) \# 100.

de volume de poros ocorre através do deslocamento e reordenação dos grânulos.

No que se refere ao efeito da granulometria do material associada à maior compactação $\left(6 \mathrm{Kgf} / \mathrm{cm}^{2}\right)$, as membranas obtidas com o pó passante em malha 100 (menor tamanho de grão, $84,93 \mu \mathrm{m}$ ) apresentaram fluxos inferiores $\left(194,62 \mathrm{~m}^{3} / \mathrm{m}^{2}\right.$ dia.bar) aos obtidos $\left(749,86 \mathrm{~m}^{3} / \mathrm{m}^{2}\right.$ dia.bar) em membranas manufaturadas com o pó passante em malha 80 (maior tamanho de grão, 120,30 $\mu \mathrm{m}$ ). Em princípio, quanto menor o tamanho de partículas, melhor a compacidade do material e menor o tamanho dos poros gerados após a sinterização. Os resultados obtidos através das medidas de fluxo do permeado confirmam esta premissa.

Quanto ao aumento na temperatura de sinterização, para estas mesmas condições de compactação $\left(6 \mathrm{Kgf} / \mathrm{cm}^{2}\right)$ e granulometria (malhas 80 e 100), observou-se que houve reduções de fluxos do permeado mais acentuadas para as membranas produzidas com pó passante em malha $100\left(103,45 \mathrm{~m}^{3} / \mathrm{m}^{2}\right.$ dia.bar $)$

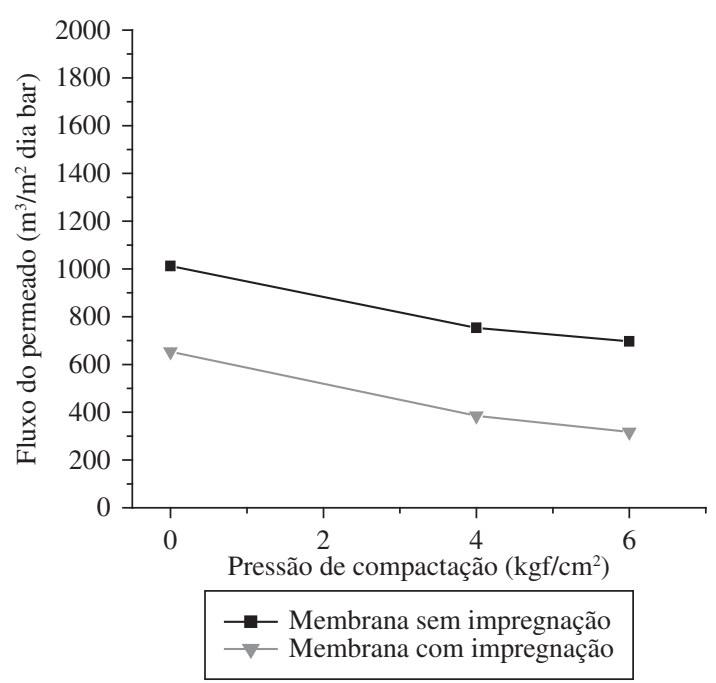

(a)

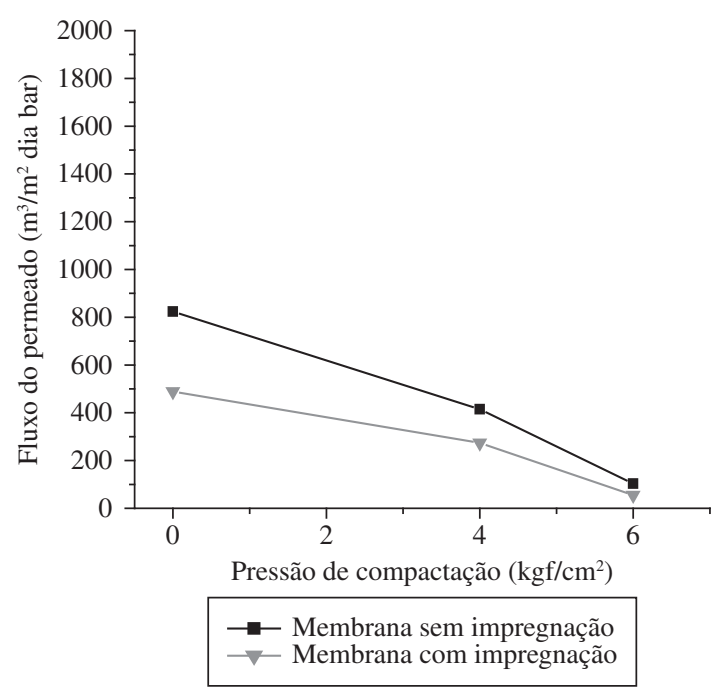

(b)

Figura 8. Efeito da compactação e da deposição de um filme de PEAD no fluxo permeado com água destilada das membranas de PEUAPM 3041sinterizadas a $220^{\circ} \mathrm{C}$ durante 90 minutos: a) \# 80; e b) \# 100

e menos acentuadas para as membranas produzidas com pó passante em malha $80\left(696,74 \mathrm{~m}^{3} / \mathrm{m}^{2}\right.$ dia.bar $)$. Este comportamento reforça a idéia de que partículas menores associadas a maior temperatura de sinterização levam a uma redução na porosidade, devido ao maior empacotamento das partículas, principalmente quando estas são submetidas às pressões de compactação mais elevadas.

A impregnação da solução de PEAD na superfície interna da membrana de PEUAPM, promoveu uma acentuada redução nos fluxos de água permeada através das membranas. Em especial, reduções mais pronunciadas foram observadas para as membranas manufaturadas sob maior temperatura $\left(220{ }^{\circ} \mathrm{C}\right)$, maior pressão de compactação $\left(6 \mathrm{Kgf} / \mathrm{cm}^{2}\right)$ e menor granulometria (peneira de malha 100), cujo fluxo foi de $55 \mathrm{~m}^{3} / \mathrm{m}^{2}$ dia.bar. Este comportamento foi tido como indicativo de que a impregnação reduziu o tamanho dos poros na 


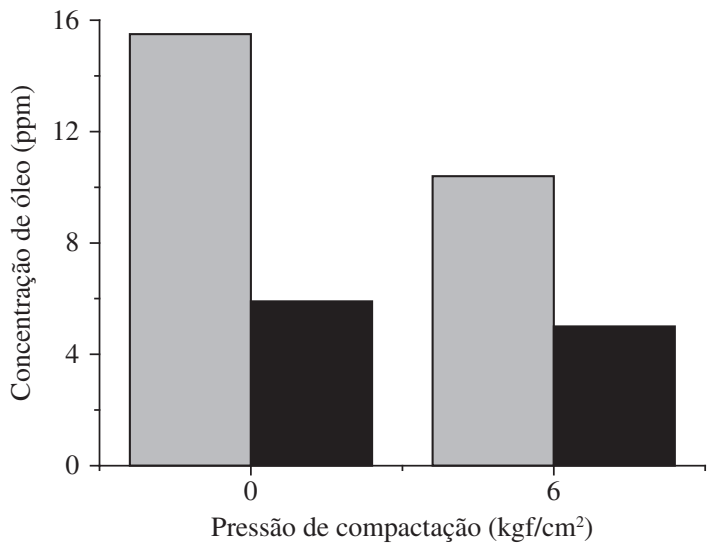

$\square$ Sem recobrimento Com recobrimento 1,0 g. $\mathrm{L}^{-1}$

(a)

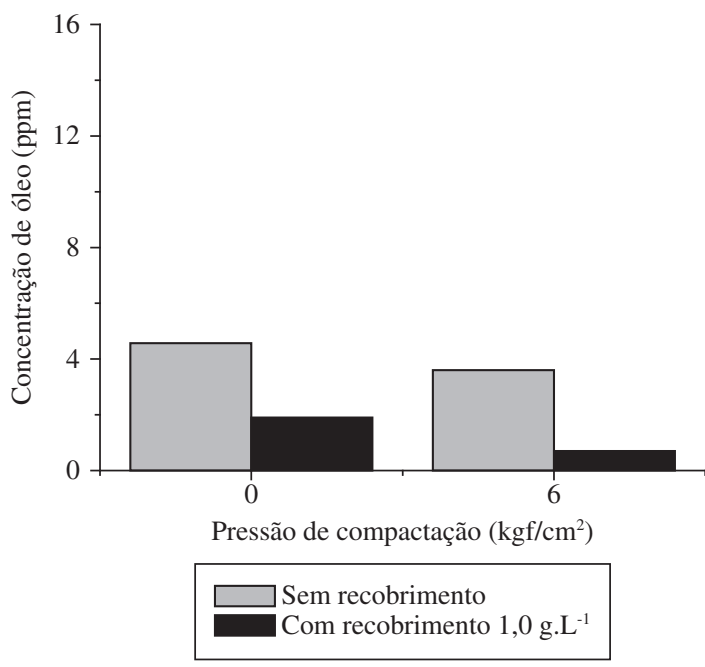

(b)

Figura 9. Efeitos da pressão de compactação e da impregnação da superfície interna das membranas na concentração de óleo permeado através de membranas sinterizadas a $220{ }^{\circ} \mathrm{C}$ durante 90 minutos com pó de PEUAPM passante em: a) malha 80; e b) malha 100.

superfície interna da membrana. Os resultados obtidos através das medidas de fluxo e das caracterizações, apresentadas nas Figuras 6 e 7, confirmam esta premissa que também foi corroborada no ensaio de seletividade, ilustrado na Figura 9, que demonstraram que membranas impregnadas apresentaram maior seletividade $(0,7 \mathrm{ppm})$ do que as não impregnadas (3,6 ppm) manufaturadas sob as mesmas condições experimentais. Os resultados dos ensaios de porosimetria de mercúrio em membranas impregnadas não foram satisfatórios quando submetidos, haja vista que a camada impregnada apresenta um volume de poros muito pequeno e o resultado fica mascarado pelo grande volume de poros da camada de suporte.

\section{Avaliação da seletividade}

Com base nos resultados obtidos para os fluxos dos permeados, realizados com água pura, membranas foram selecionadas para avaliação quanto à seletividade.
Os resultados obtidos indicam que a aplicação de elevadas pressões de compactação, seguida da impregnação da superfície interna das membranas com solução de PEAD em tolueno levaram, respectivamente, à redução da porosidade e do tamanho dos poros das membranas, o que implica em elevada seletividade das membranas.

A elevada seletividade das membranas que não foram sujeitas à compactação ou à impregnação por solução de PEAD, é justificada pelo fenômeno de polarização de concentração. Este fenômeno que é favorecido pela crescente concentração da fase dispersa próxima à superfície da membrana, aumentando, a possibilidade de coalescência, acúmulo e obstrução superficial dos poros, levando à redução dos mesmos e elevando a seletividade. Segundo Mueller (1997) ${ }^{[15]}$ o aumento da resistência à passagem das gotículas de óleo é ocasionada pela contaminação na superfície e nos poros da membrana e não pela membrana em si.

Os resultados de seletividade indicaram que as membranas sinterizadas são suficientemente seletivas para o descarte de águas contaminadas por óleo mas que esta seletividade é aumentada quando estas são compactadas após a sinterização e modificadas superficialmente, pois a concentração de óleo no permeado se encontra muito abaixo do valor máximo permitido pelo CONAMA $\left(357 / 07 /<20 \mathrm{mg} \cdot \mathrm{L}^{-1}\right)$.

\section{Conclusões}

Membranas de PEUAPM foram obtidas. A separação granulométrica do material promoveu uma redução do tamanho de grãos, proporcionando sua melhor compactação e, portanto, redução do fluxo do permeado através do material manufaturado com o pó de menor faixa granulométrica. A compactação após a sinterização levou a maiores reduções no fluxo e na porosidade das membranas, enquanto o tamanho médio dos poros permaneceu inalterado.

A impregnação da superfície interna das membranas com solução de PEAD promoveu reduções de fluxos ainda mais acentuadas se comparados aos obtidos com as membranas simétricas, isto é, com as membranas cuja superfície interna não foi modificada.

De um modo geral, o estudo realizado nos permite confirmar que o processo de sinterização é viável para a confecção de membranas de PEUAPM. A capacidade das membranas de PEUAPM em remover óleo presentes em água foi comprovada, indicando que o uso deste material pode se tornar mais uma ferramenta promissora para tratamento de efluentes.

\section{Agradecimentos}

À BRASKEM pela doação da matéria-prima, ao PRH25 da ANP/UFCG pelo apoio financeiro a bolsa IC/ANP em favor de Alves; ao CNPq/CTpetro pela bolsa PROSET concedida a Leal e ao CNPq pela bolsa PQ em favor de Carvalho e Lira. 


\section{Referências Bibliográficas}

1. Mulder, M. - Basic Principles of Membrane Technology, Kluwer Academic Publishers, Boston 1991.

2. Carvalho, R. B.; Borges, C. P. \& Nóbrega, R. - Formação de membranas planas celulósicas por espalhamento duplo para os processos de nanofiltração e osmose inversa. Polímeros: Ciência e Tecnologia, 11, (2), p.65-75. (2001).

3. Porter, M. C. - "Handbook of industrial membrane technology". NUEVA Jersey, U.S.A. Noyes Publications, 1990.

4. Nouzaki, K.; Nagata, M.; Arani, J.; Idemoto, Y.; Koura, N.; Yanagishita, H.; Negishi, H.; Kitamoto, D.; Ikegami, T. \& Haraya, K. - Desalination, 144, p.53-59, (2002).

5. As-nguanruksa, J.; Rujiravanit, R.; Supaphol, P. \& Tokura, S. - Polymer Testing, 23, p.91-99 (2004).

6. Habert, A. C.; Borges, C. P. \& Nóbrega, R. - in: Processos de separação por membranas, Ed.E-papers, 1, p.10-25 (2006).

7. Porter, M. C. - Handbook of Industrial membrane techonology, 5, p.5-9, (1999).

8. Crosby, J. - (Org.) "Chirality in industry II: Developments in the manufacture and applications of optically active compounds". Chichester, England. John Wiley \& Sons Ltd, p.157-180, 1997.

9. Leal, T. L. - Tese de Doutorado, 2007, Universidade Federal de Campina Grande.

10. BRASKEM - Boletim técnico 6, 1998, São Paulo, Brasil.

11. Souto, K. M.; Carvalho, L. H. \& Lira, H. L. - XV Congresso Brasileiro de Engenharia e Ciências dos Materiais, Natal-RN, 2002.

12. Tadmor, Z. \& Gogos, C. G. - Principles of polymer processing, John Wiley \& Sons, New York, 1979.

13. Kahyet, M.; Suk, D. E.; Narbaitz, R. M.; Sauterre, J. P. \& Matsuura, T. - Journal applied polymer Science, 89, p.2902-2916 (2002).

14. Alves, T. S.; Carvalho, L. H.; Lira, H. L. \& Leal, T. L. - in: Proceedings of the XI International Macromolecular Coloquium/6th International Symposium on Natural Polymers and Composites, Gramado, 2007, 1, CD-Rom.

15. Mueller, J.; Yanvey, C. \& Davis, R. H. - Journal of Membranes Science, (129), p.221-235 (1997).

16. Islabão, G. I. - Dissertação de mestrado, 2005, UFRGS.

Enviado: $14 / 12 / 07$

Reenviado: $24 / 07 / 08$

Aceito: $17 / 11 / 08$ 